\title{
Perancangan Website Sekolah pada SDN 103 Kabupaten Sinjai sebagai Salah Satu Sarana Pembelajaran Online dan Penyajian Informasi
}

\author{
Nahlah $^{1, \mathrm{a}}$, Amiruddin ${ }^{1, \mathrm{~b}}$ dan Farida Amansyah ${ }^{1, \mathrm{c}}$ \\ 1 Jurusan Administrasi Niaga, Politeknik Neg. Ujung Pandang, Jl. Perintis Kemerdekaan Km 10, Makassar, 90245,Indonesia \\ a nazizah12@gmail.com \\ b amirbagus@yahoo.co.id \\ c faridaamansyah@yahoo.com
}

\begin{abstract}
The existence of school's website is a necessity that can not be avoided anymore. School's website is very useful as one of online learning and information presenting medium and also as a prerequisite for some inter-schools competition. Without the school's website, a school can not be a winner in a particular competition, like "Fund Management of School Operation Assistance". This situation has been experienced by the State Elementary School 103 Sinjai which failed to get the championdue to unavailability of the school website. This research aims to design a school website for the State Elementary School 103 Sinjai. The website that will be created uses PHP and MySQL-based CMS. Content and features of the website is created as the result of interviews with school's parties. The collecting of data was done by observation, documentation, and literature study. The softwares that used were Xampp, Dreamweaver Macromedia, one of isntallation package of $\mathrm{PHP}$, Apache web server, and MySQL, as well as Research and Development's CMS. After installation of the softwares and Research and Development's CMs was completed, it was followed by adjustment of website content by logging in to the admin page. The created website has domain link as follows : http://sdn103sinjai.sch.id which has been published since the beginning of May 2016 and has been used by school parties in providing information about the various (all sort of) school activities.
\end{abstract}

Keywords: CMS; Balitbang; and school website

Abstract-Keberadaan website sekolah merupakan kebutuhan yang tidak dapat dihindari lagi. Website sekolah sangat bermanfaat sebagai salah satu sarana pembelajaran online dan sarana penyajian informasi, dan menjadi prasyarat beberapa lomba antar sekolah. Tanpa website sekolah, sebuah sekolah tidak bisa mendapatkan predikat juara dalam perlombaan tertentu, seperti perlombaan "Pengelolaan Dana Bos". Hal ini telah dialami oleh SDN 103 Kabupaten Sinjai yang gagal mendapatkan predikat juara karena tidak memiliki website sekolah. Penelitian ini bertujuan merancang sebuah website sekolah pada SDN 103 Kabupaten Sinjai. Website yang akan dibuat ini menggunakan CMS berbasis PHP dan MySQL.
Isi dan fitur dalam website dibangun atas hasil wawancara dengan pihak sekolah. Pengumpulan data dilakukan dengan observasi, dokumentasi dan studi pustaka. Perangkat lunak yang digunakan adalah XAMPP, Macromedia Dreamweaver, salah satu paket instalasi PHP, Apache webserver, dan MySQL, serta CMS Balitbang. Setelah instalasi perangkat lunak dan CMS Balitbang selesai, dilanjutkan dengan penyesuaian isi website dengan melakukan login pada halaman admin. Website yang dihasilkan berdomain http://sdn103sinjai.sch.id telah dipublish sekitar awal bulan 5 tahun 2016 dan telah dimanfaatkan oleh pihak sekolah dalam menyajikan berbagai informasi tentang berbagai kegiatan-kegiatan sekolah.

Kata Kunci: CMS; Balitbang; dan Website SD.

\section{Pendahuluan}

\section{A. Latar belakang}

Penelitian ini dirancang dengan tujuan membangun sebuah website di SDN 103 Kabupaten Sinjai. Kebutuhan akan website di sekolah-sekolah yang dapat menampilkan berbagai informasi tentang sekolah, pendidikan, kegiatan-kegiatan sekolah, serta berbagai artikel pengetahuan, dan lain-lain menjadi sangat penting sehingga tidak salah jika pihak Dinas Pendidikan telah menjadikan kepemilikan "website" sebagai salah satu syarat menjadi pemenang dalam beberapa kegiatan lomba antar sekolah.

Website sekolah yang akan dibuat menggunakan CMS (Content Management System) berbasis PHP dan MySQL. CMS yang akan digunakan adalah CMS Balitbang dengan domain SCH.ID. Berdasarkan uraian di atas, maka permasalahan penelitian ini adalah bagaimana cara membangun sebuah "website sekolah" 
pada SDN 103 Sinjai yang bisa bermanfaat sebagai sarana pembelajaran online dan penyajian informasi dengan menggunakan CMS. Beberapa penelitian yang berhubungan dengan "website sekolah" diantaranya Pembuatan website resmi Sekolah Menengah Kejuruan Negeri 3 Madiun oleh Septian Dwi Saputra Program D3 Ilmu Komputer Fakultas Matematika dan Ilmu Pengetahuan Alam Universitas Sebelas Maret Surakarta 2010.

\section{B. Pengertian CMS}

CMS adalah singkatan dari Content Management System. CMS merupakan sebuah aplikasi web atau software web yang tujuannya untuk memudahkan dalam pengelolaan (upload,edit,menambahkan,dan lain-lain) konten dalam sebuah website/blog/aplikasi web tanpa harus dibekali pengetahuan tentang hal-hal yang bersifat teknis atau memiliki pengetahuan tentang bahasa pemrograman web yang handal sehingga dengan adanya CMS ini, orang awam pun dapat membuat sebuah website yang langsung jadi dan pengguna tinggal mengelola isi konten website tersebut tanpa campur tangan dari pihak webmaster [1][2].

\section{Pengertian PHP}

PHP (Personal Home Page Tools) adalah skrip pemrograman yang terletak dan dieksekusi di server. Salah satu fungsinya adalah menerima, mengolah, dan menampilkan data dari dan ke sebuah situs (website). Data akan diolah ke sebuah database server (program database yang terletak di server, misalnya MySQL) untuk kemudian hasilnya ditampilkan di browser sebuah situs. Dengan demikian PHP dapat membuat situs lebih dinamis karena data situs selalu dapat diubah sesuai permintaan. Anhar [3] mendefiniskan PHP adalah bahasa pemrograman berupa skrip yang dapat diintegrasikan dengan HTML.

\section{Sekilas tentang MySQL}

MySQL merupakan software yang tergolong sebagai DBMS (Database Management System) yang bersifat Open Source. Open Source menyatakan bahwa software ini dilengkapi dengan source code (kode yang dipakai untuk membuat MySQL), selain tentu saja bentuk executable-nya atau kode yang dapat dijalankan secara langsung dalam system operasi, dan bisa diperoleh dengan cara men-download di internet secara gratis [4].

\section{Metode Penelitian}

\section{A. Metode Penelitian}

Metode penelitian yang digunakan adalah metode penelitian terapan yaitu salah satu jenis penelitian yang bertujuan untuk memberikan solusi atas permasalahan tertentu secara praktis. Lokasi penelitian bertempat di SDN 103 Sinjai Utara Kabupaten Sinjai.

Pengumpulan data dilakukan dengan cara sebagai berikut:

1. Observasi

Yaitu metode pengumpulan data dengan cara melakukan pengamatan secara langsung pada obyek yang akan diteliti.

2. Dokumentasi

Yaitu metode pengumpulan data dengan melihat laporan yang telah ada agar diperoleh berbagai data yang dapat dijadikan referensi. Beberapa informasi yang diperlukan seperti berikut:

a. Profil Sekolah

(Sejarah, Visi dan Misi, Struktur Organisasi, Dewan Sekolah)

b. Staf Pengajar

(Daftar Guru, Riwayat Pendidikan Guru, Prestasi Guru)

c. Program Kerja

(Program Kerja, Kalender Akademik Semester Ganjil dan Genap)

d. Sarana

(Gedung, Perpustakaan, Mushola, Kantin, Lapangan Olahraga, Komputer, Parkir)

e. Kegiatan

(OSIS, Pramuka, PMR, Pecinta Alam, Studi Tour, Kegiatan Tahunan, Drum Band, Paskibraka, Kelompok Belajar)

f. Alumni

(Data Alumni, Informasi Alumni, Jadwal Reuni)

g. Galeri Photo 
(Kumpulan Photo Sekolah seperti Gedung, Sarana Sekolah, Kegiatan, Peresmian, Prestasi, Studi Tour)

h. Data Siswa

(Data Siswa yang terdiri dari Nama Siswa Kelas, NIS, Tanggal Lahir, Alamat, Nama Wali dan Alamat Tempat Tinggal )

\section{Studi Pustaka}

Yaitu metode pencarian data melalui studi literatur terhadap buku-buku yang membahas pembuatan website dan CMS.

\section{B. Rancangan Penelitian}

\section{Perancangan Sistem}

Rancangan penelitian dilakukan dengan mengimplementasikan metode waterfall dengan menggunakan diagram alir data atau Data Flow Diagram (DFD), seperti berikut:

\section{Implementasi}

Implementasi pembuatan websitenya menggunakan beberapa perangkat lunak seperti XAMPP, Macromedia Dreamweaver, salah satu paket instalasi PHP, Apache webserver, dan MySQL, serta CMS Balitbang [5].

3. Tahap Pengujian Hasil Rancangan.

Tahap ini merupakan tahap pemeriksaan terhadap aplikasi yang telah dibuat. Pengujian dilakukan dengan menginput data pada setiap menu yang telah dirancang dan mengecek semua tombol-tombol menu perintah. Jika tidak berfungsi dengan baik akan dilakukan pengecekan ulang terhadap aplikasi yang tidak berfungsi. Jika aplikasi telah berfungsi dengan baik maka hasil rancangan siap digunakan.
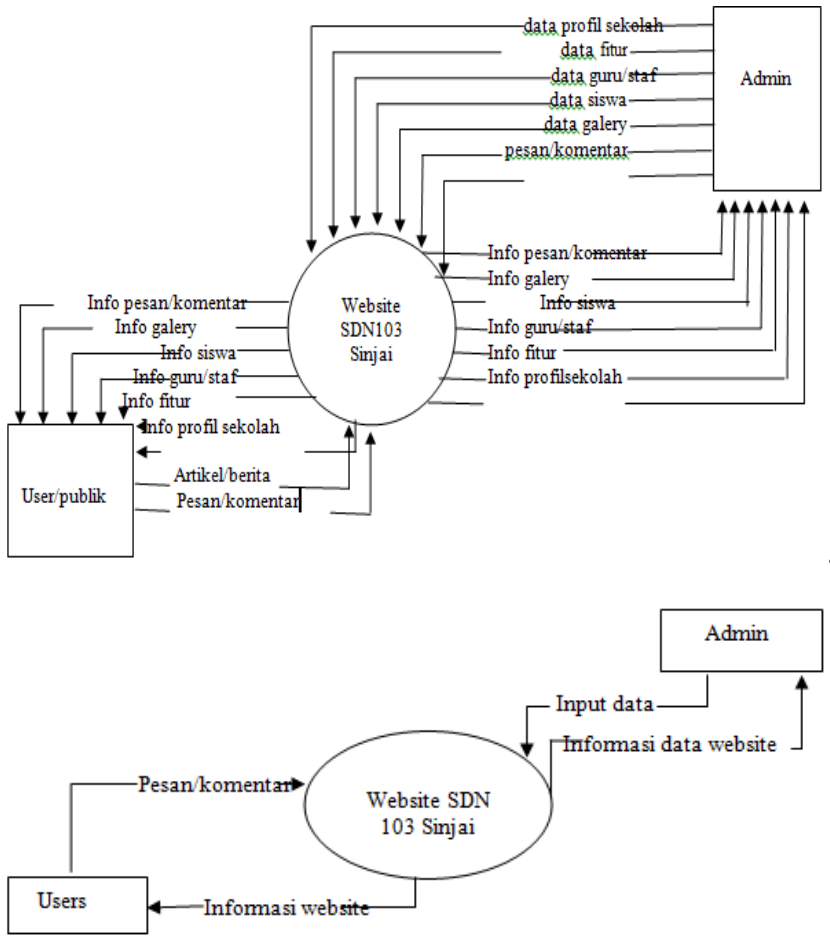

Gambar 1. Diagram Konteks

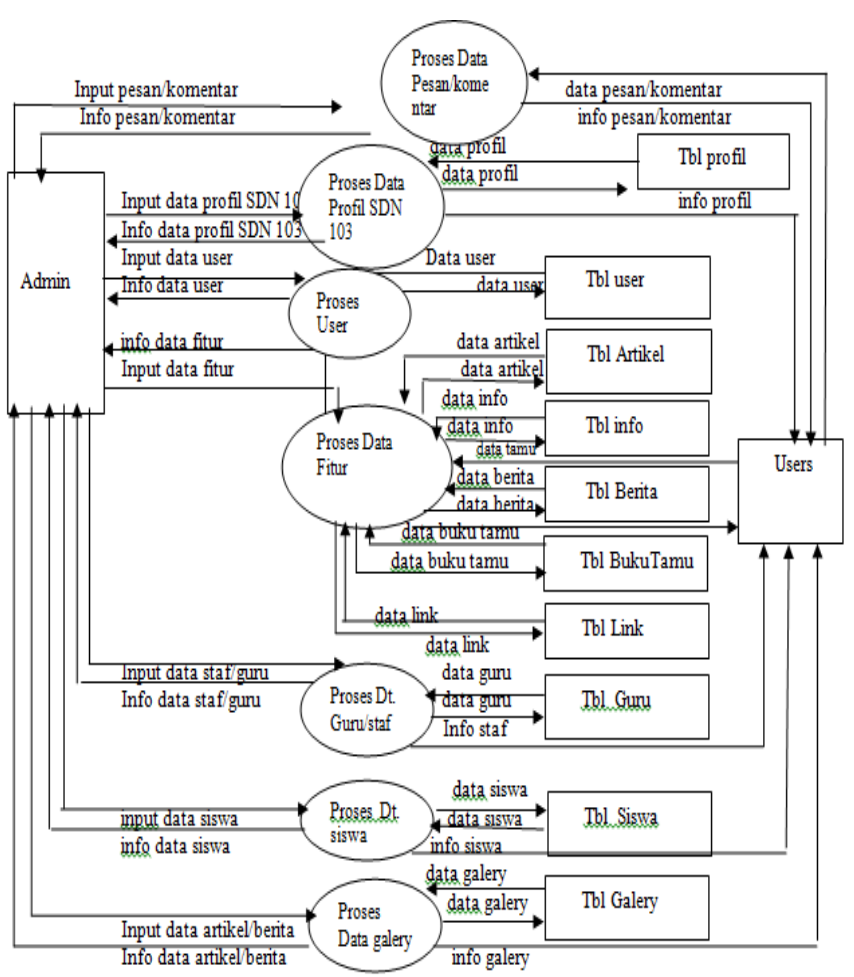

Gambar 2. Diagram Admin Level 1 


\section{Hasil dan Pembahasan}

\section{A. Perancangan Website Sekolah}

Untuk membangun website sekolah sebagaimana yang telah dijelaskan pada bab sebelumnya, perlu dilakukan dua tahapan instalasi yaitu:

1. Instalasi Web Server

2. Instalasi Web Sekolah

Penjelasan masing-masing tahapan sebagai berikut:

1. Instalasi Web Server

Web server adalah sebuah perangkat keras dan perangkat lunak yang merupakan aplikasi utama untuk menyimpan dan mengirimkan dokumen web (HTML, PHP, ASP, JSP). Untuk melakukan instalasi web server diperlukan beberapa perangkat antara lain:

Perangkat Keras

1. Unit PC Calon Server Web

2. Perangkat Jaringan (Kabel UTP, Switch/Hub, Ethernet)

Perangkat Lunak

1. Sistem Operasi (WindowsXP, Windows 2000, Windows 2003)

2. Perangkat Lunak (XAMPP, Appserv, PHPTriads)

Dalam penelitian ini digunakan sistem operasi WindowsXP dan perangkat lunak XAMPP. Setelah penginstalan XAMPP dilanjutkan dengan penginstalan PHP, MySQL dan Apache.

\section{Instalasi Web Sekolah}

Setelah selesai instalasi web server dilanjutkan dengan instalasi website sekolah. Website sekolah yang diinstal ini menggunakan CMS Balitbang, hasil karya putra Indonesia. CMS Balitbang adalah sebuah CMS yang dibuat oleh Kemenristek RI yang memang dikhususkan untuk pembuatan sistem informasi berbasis website untuk sekolah-sekolah di Indonesia.

Hasil instalasi diletakkan pada sebuah folder dengan nama SDN 103 yang diletakkan pada sebuah folder yang bernama htdocs. Htdocs adalah subfolder dari Xampp.

Selanjutnya buat database pada:

http://localhost/phpmyadmin.

Databasenya dinamakan juga SDN 103. Setelah itu dilanjutkan dengan pengimporan file-file dari hasil installasi website sekolah pada database yang telah dibuat. Kemudian buka browser dan ketikkan http://localhost/sdn103.

Akan tampil gambar seperti berikut:

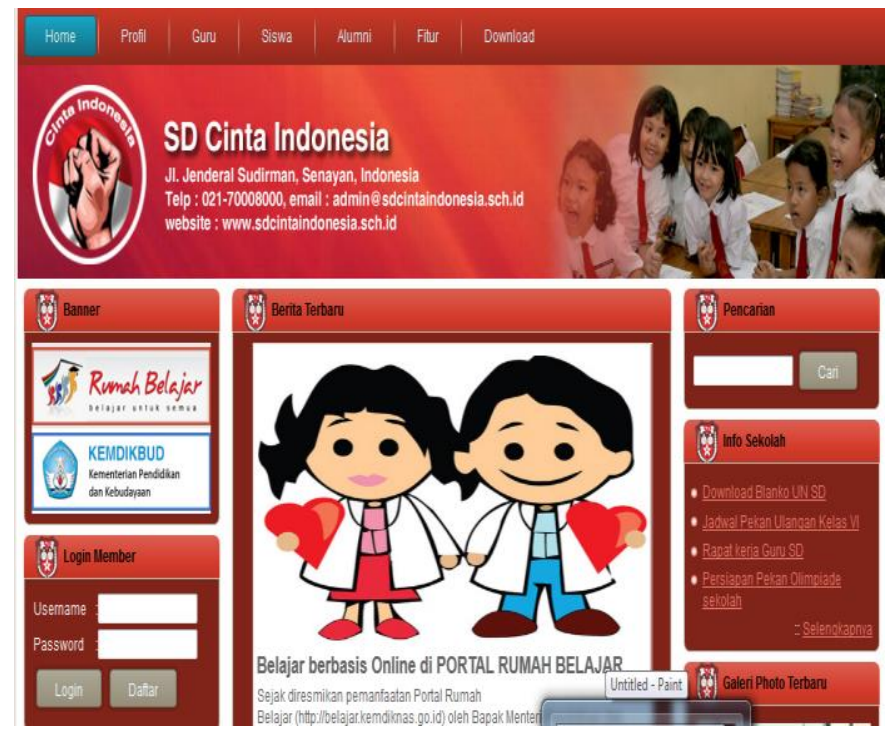

Gambar 3. Tampilan Awal Website CMS

Selanjutnya, akan dilakukan penyesuaian isi website dengan melakukan login pada browser dengan mengetik: http://localhost/sdn103/admin.

Masukkan Username dan Password dengan nama "admin" pada gambar berikut:

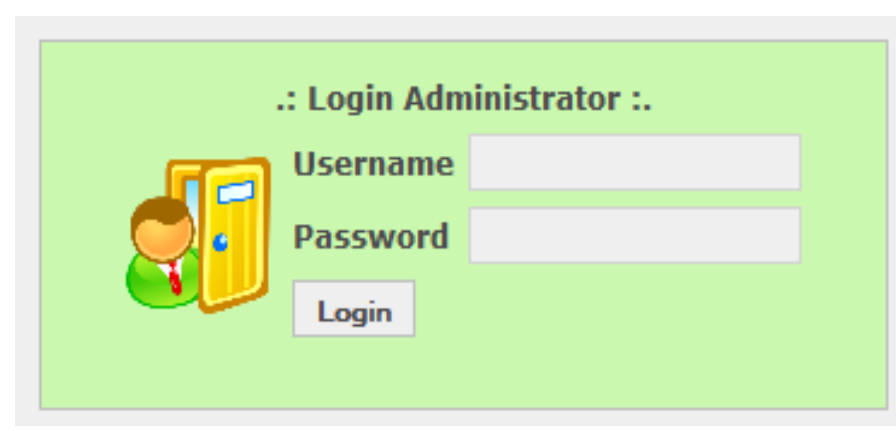

Gambar 4. Login Administrator 
Jika login sukses maka akan tampil gambar berikut:

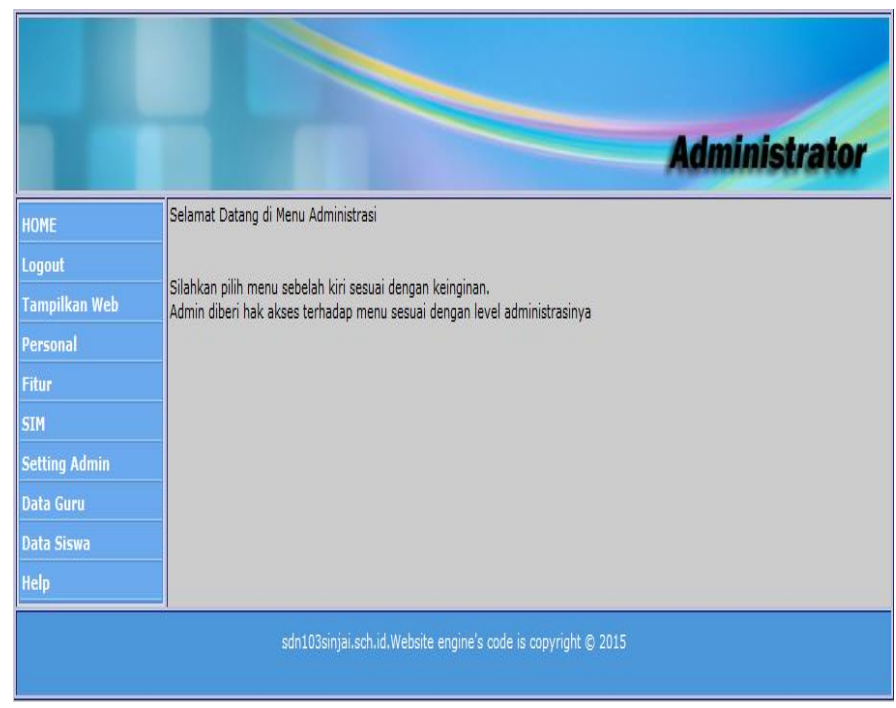

Gambar 5. Halaman Admin

Tampilan gambar di atas merupakan halaman utama admin untuk mengedit isi dan tampilan website sekolah.

Pertama-tama yang bisa dilakukan adalah mengelola bagian utama yang meliputi 3 kategori pokok, yakni:

1. Mengelola Admin

2. Mengubah Desain Banner Atas

3. Melengkapi Profil Sekolah

\section{B. Manual Program Aplikasi}

Setelah dilakukan berbagai penyesuaian maka dapat dihasilkan sebuah website yang diinginkan dengan tampilan awal secara offline sebagai berikut:

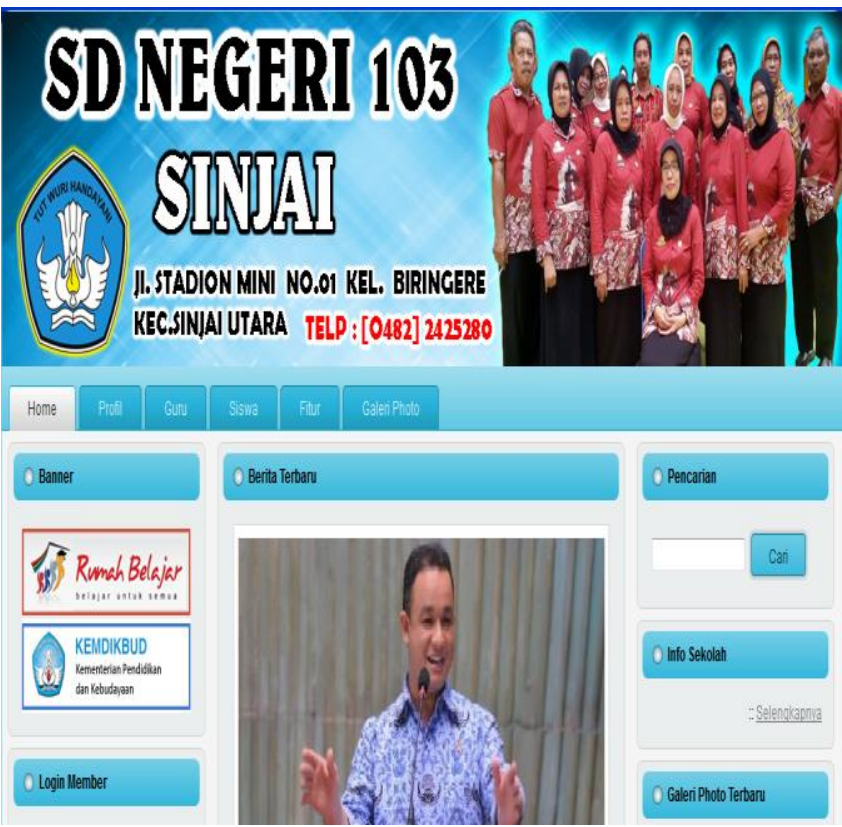

Gambar 6. Tampilan Awal Website SDN 103 Sinjai

Selanjutnya pada menu "profil" akan ditampilkan beberapa data yang bersifat "statis" seperti visi misi, sejarah singkat, sarana dan prasarana. Lengkapnya dapat dilihat pada gambar berikut ini:

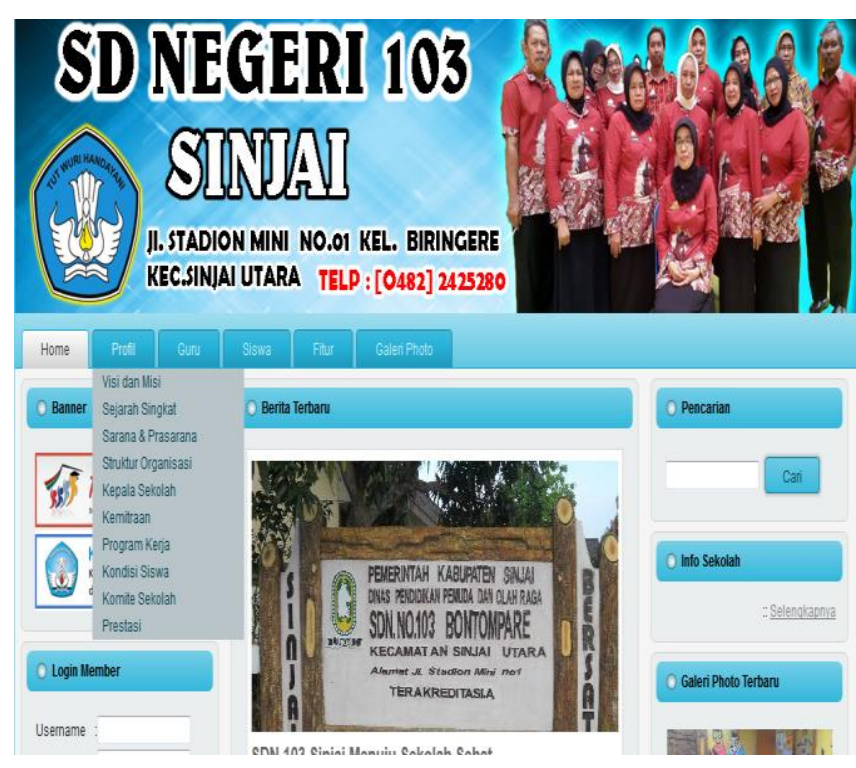

Gambar 7. Tampilan Menu Profil Website SDN 103 Sinjai 


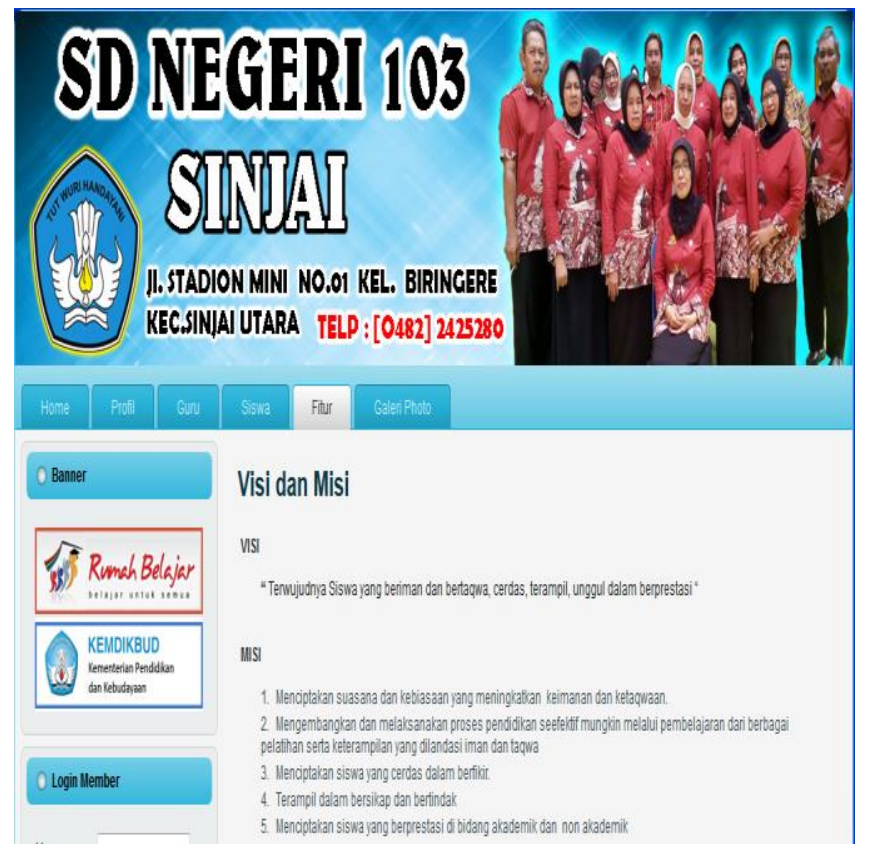

Gambar 8. Tampilan Visi dan Misi Website SDN 103 Sinjai

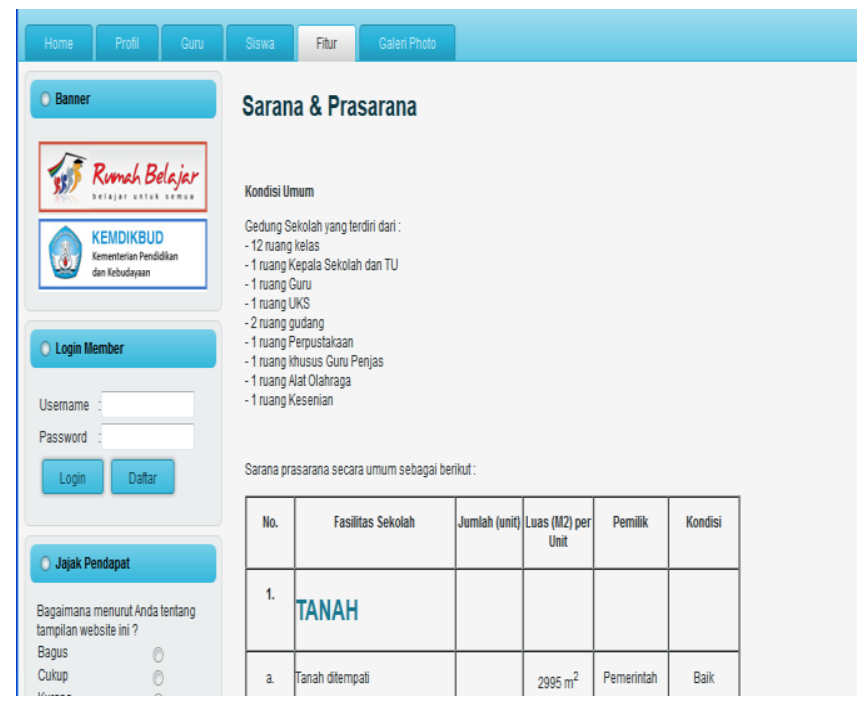

Gambar 9. Tampilan Sarana dan Prasarana Website SDN 103 Sinjai
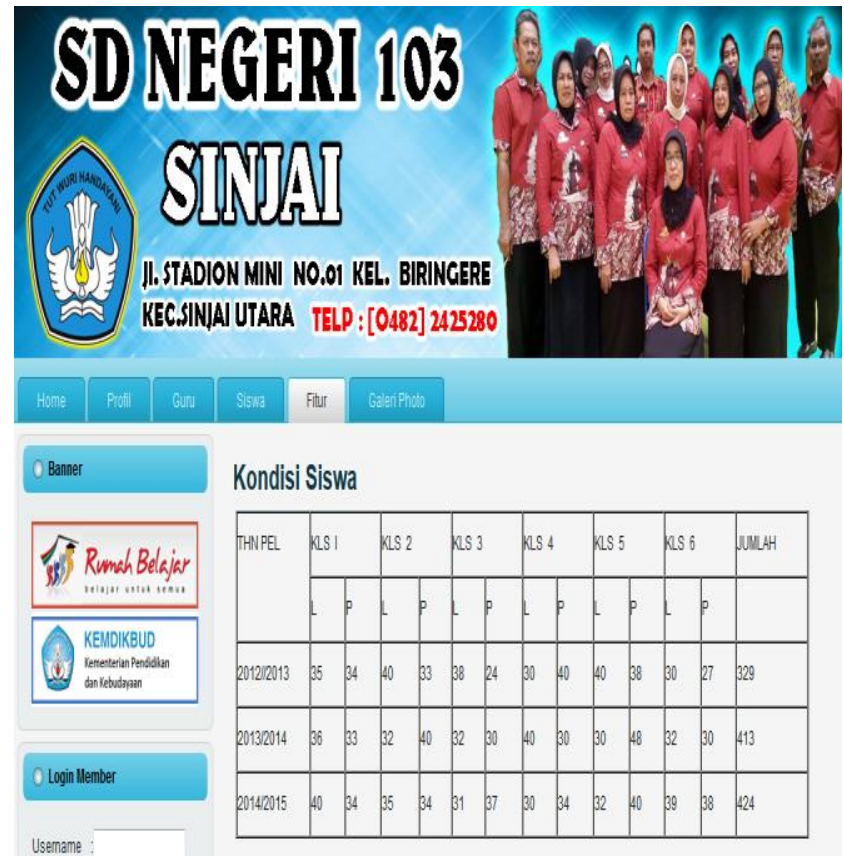

Gambar 10. Tampilan Kondisi Siswa Website SDN 103 Sinjai

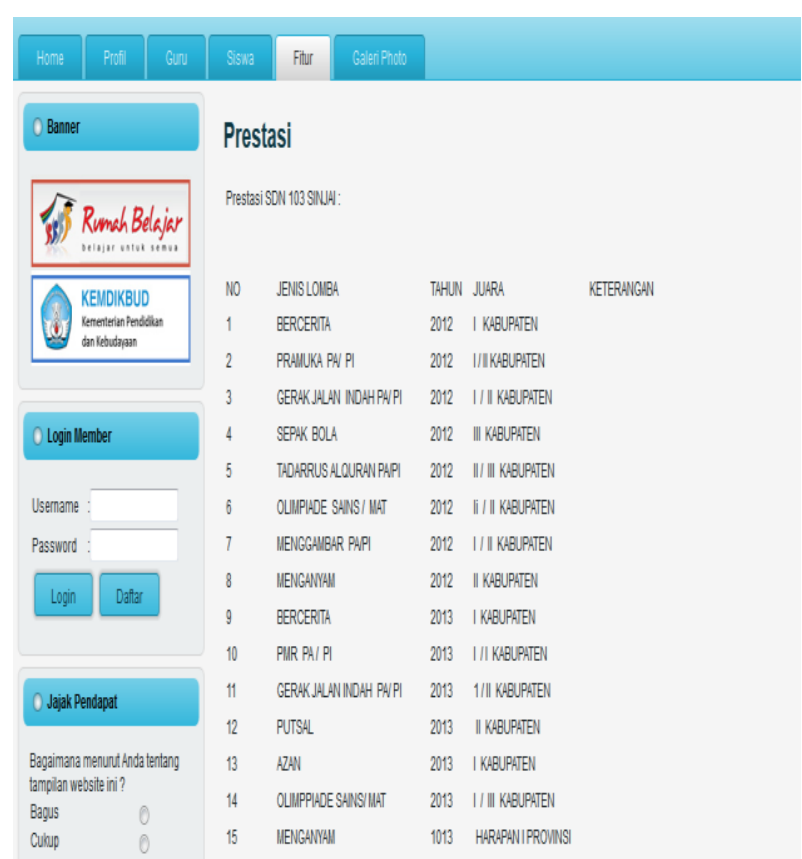

Gambar 11. Tampilan Prestasi Siswa Website SDN 103 Sinjai 


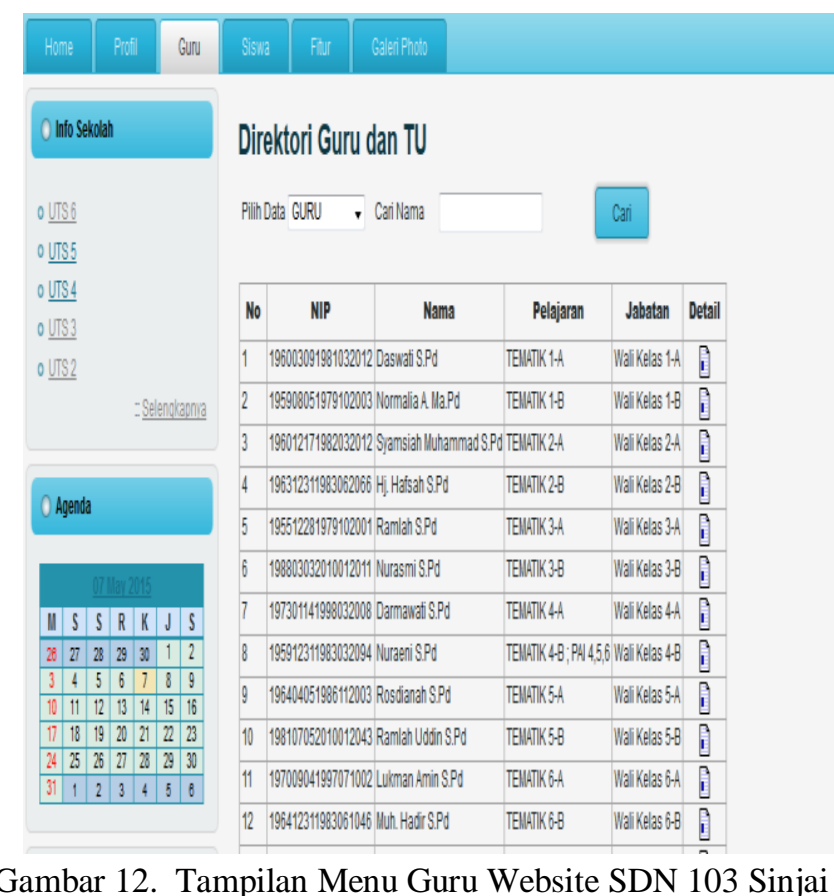

Gambar 12. Tampilan Menu Guru Website SDN 103 Sinjai
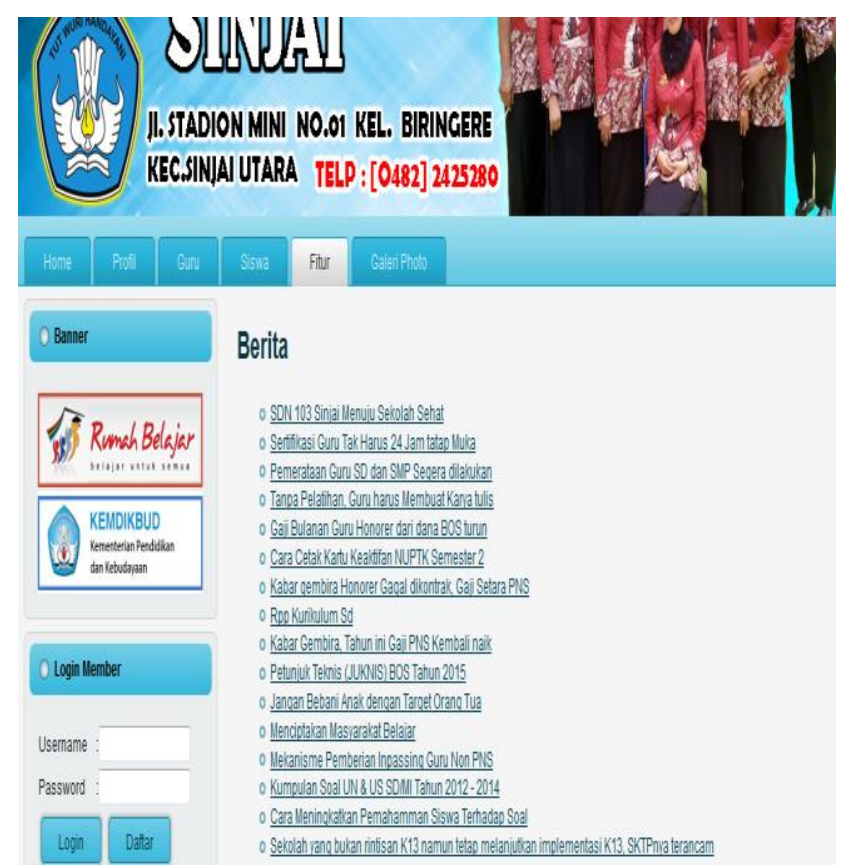

Gambar 13. Tampilan Berita pada Menu Fitur Website SDN 103 Sinjai

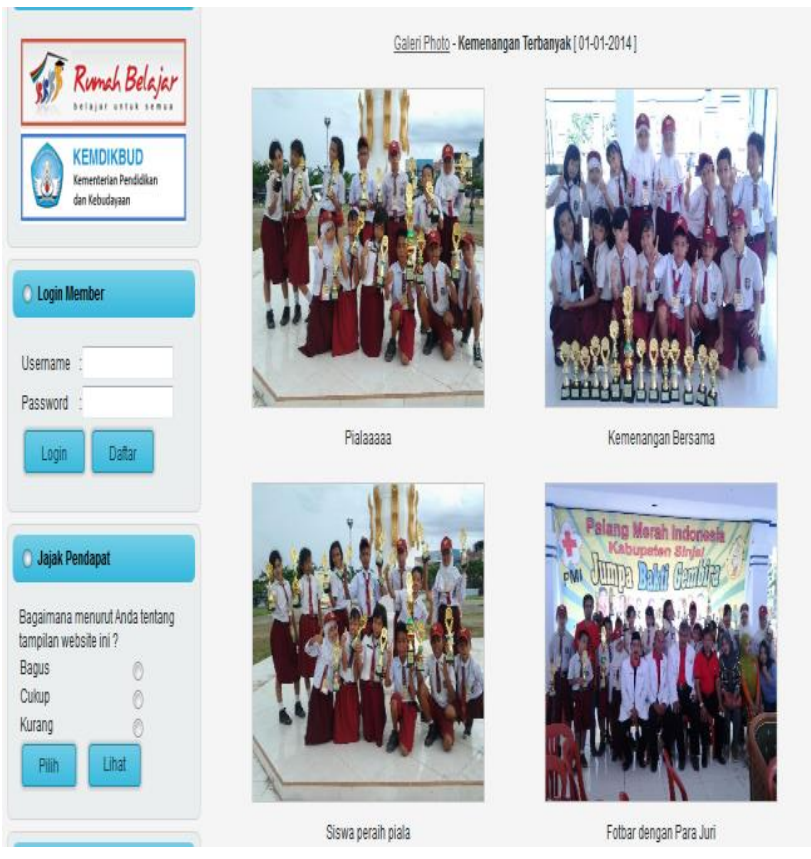

Gambar 14. Salah satu isi galery pada menu fitur website SDN 103 Sinjai

\section{Kesimpulan}

\section{A. Kesimpulan}

1. Website Sekolah Negeri 103 Sinjai telah dihasilkan dengan menggunakan CMS (Content Management System) milik balitbang yang khusus buat pengadaan website di sekolah-sekolah. Perancangan sistem dilakukan dengan menggunakan konsep diagram konteks, Data Flow Diagram (DFD), dan Entity Relationship Diagram (ERD).

2. Website ini telah digunakan oleh pihak sekolah secara online dengan nama http://sdn103sinjai.sch.id. Dari hasil diskusi dengan pengguna, diperoleh informasi bahwa website ini telah dirasakan manfaatnya dengan adanya apresiasi beberapa pihak yang berkepentingan dengan informasi yang disajikan dalam website tersebut. 


\section{B. Saran}

Saran buat admin website adalah agar senantiasa men-update data-data atau informasi yang terbaru agar manfaat website senantiasa terjaga dan dirasakan khususnya oleh pihak-pihak yang membutuhkan informasi dari sekolah dengan kemudahan mendapatkan informasi yang terkini.

\section{Ucapan Terima Kasih}

Terima kasih yang sebesarnya disampaikan kepada Kemenristek Dikti atas dana yang telah diberikan untuk kegiatan penelitian ini dan juga kepada pihak UPPM yang telah memfasilitasi pelaksanaan penelitian ini hingga selesai.

\section{Daftar Pustaka}

[1] Virmansyah. 2012. Pengertian CMS dan Macam-Macamnya http://www.virmansyah.info/2012/11/pengertian-cms-danmacam-macamnya.html. 25 April 2015.

[2] Saputra,Agus dan Feni Agustin.2011.Pemrograman CSS untuk Pemula.Jakarta: PT Elex Media Komputindo.

[3] Anhar. 2010. Panduan Menguasai PHP dan MySql secara Otodidak. Jakarta: Mevdiakita.

[4] Kadir, Abdul. 2008. Belajar Database Menggunakan MySQL. Yogyakarta: Andi offset.

[5] Wahana Komputer. 2011.Mastering CMS Programming with PHP \& MySQL.Yogyakarta: Andi Offset 